\title{
Exploration of Eating Disorders, Nutritional and Health Status Based on Eating Attitude Test-26 amongst University Adolescent Girls
}

\author{
Ayesha Syed ${ }^{1, *}$, Falak Zeb ${ }^{1,2, *}$, Saleem Khan ${ }^{1}$, Mahpara Safdar ${ }^{3}$, Iftikhar Alam ${ }^{4}$, Muhammad Shahzad ${ }^{5}$, \\ Fazli Akbar ${ }^{1}$, Feng Qing ${ }^{2}$, Xiaoyue $\mathrm{Wu}^{2}$, Masooma Munir ${ }^{6}$ \\ ${ }^{1}$ Department of Human Nutrition, Faculty of Nutrition Sciences, The University of Agriculture Peshawar, Pakistan \\ ${ }^{2}$ Department of Nutrition and Food Hygiene, School of Public Health, Nanjing Medical University Jiangsu, China \\ ${ }^{3}$ Department of Home and Health Sciences, Faculty of Sciences, Allama Iqbal Open University Islamabad, Pakistan \\ ${ }^{4}$ Department of Clinical Nutrition, College of Community Health, King Saud University, Saudi Arabia \\ ${ }^{5}$ Institute of Basic Medical Sciences, Khyber Medical University Peshawar, Pakistan \\ ${ }^{6}$ Institute of Food Science and Nutrition, University of Sargodha, Sargodha, Pakistan \\ *Corresponding author: ayeshasyed789@gmail.com; falak106@gmail.com
}

\begin{abstract}
Eating disorder causes serious disturbances in behaviors related to nutrition in adolescent. Although most of these attitudes are benign, they can bear significant psychological and health risks. A cross-sectional study was conducted on 250 university adolescent girls studying in Peshawar Pakistan to explore their eating disorder, nutritional and health status. Girls were interviewed for eating attitudes by using Eating Attitude Test (EAT-26), socio-economic status and body image. Anthropometric and biochemical indices were measured. Based on EAT-26 scale, girls with and without eating disorders were identified. In both groups the association between anemia and risk factors was evaluated. Health and nutritional risk factors for anemia in girls were identified by applying logistic regression. Mean score of EAT-26 was $18 \pm 10.5$ while for Dieting, Bulimia, Oral Control and Body Image of the girls was $8.5 \pm 7,3.20 \pm 2.59,6.36 \pm 4.41$ and $20 \pm 9$ respectively. EAT-Score was found in strong association with anemia in unadjusted and adjusted analysis. Among the health factors, girls with symptoms of anxiety, depression and stress were more likely anemic than their counterpart. More anorexic girls were found overweight and obese in comparison to the rest $(\mathrm{p}<0.05)$. Body shape being android or gynoid as well as anemia were found similar among the groups ( $>0.05$ ). More anorexic girls showed significant difference in less freshness, disrupted sleep and low physical activity $(\mathrm{p}<0.05)$. It has been concluded that eating disorders (anorexia) are more prevalent in university adolescent girls and could adversely affect the health and nutritional status of the students.
\end{abstract}

Keywords: eating attitude, anorexia, anemia, gynoid, bulimia, body image score

Cite This Article: Ayesha Syed, Falak Zeb, Saleem Khan, Mahpara Safdar, Iftikhar Alam, Muhammad Shahzad, Fazli Akbar, Feng Qing, Xiaoyue Wu, and Masooma Munir, "Exploration of Eating Disorders, Nutritional and Health Status Based on Eating Attitude Test-26 amongst University Adolescent Girls." Journal of Food and Nutrition Research, vol. 6, no. 7 (2018): 464-470. doi: 10.12691/jfnr-6-7-7.

\section{Introduction}

Disordered eating attitudes refer to many unhealthy eating patterns which affect the nutritional and health status of adolescent girls [1]. The literature shows that adolescent girls are more prone to adopt various forms of eating attitudes than boys [2], because they become preoccupied with and sensitive to their changing body size, shape, and physical appearance. Many studies have found that adolescent girls are interested in losing weight and more than $40 \%$ have even tried to lose weight due to concern over their body weight [3]. Disturbed eating attitudes are associated with a number of harmful behaviours such as smoking, alcohol consumption, taking supplements, and suicide as well as physical, physiological and psychosocial consequences like poorer dietary quality, depressive symptoms, weight gain and obesity [4], and finally the onset of eating disorders [5].

The eating disorders including anorexia nervosa and bulimia nervosa arise from a complex interaction of biological, psychological and social processes, and are an important cause of physical and psychosocial morbidity in adolescent girls and young women [6]. Prevalence of anorexia nervosa and bulimia nervosa have increased among adolescents in Arabic, Western [7] and now a clinical problem in Asian countries like Pakistan, India and Bangladesh etc. Nearly $50 \%$ of adolescents had the chance to become overweight during the transition to adulthood [8]. Anorexia nervosa is an increasingly common eating disorder in adolescent girls, in Western societies [9], and is the third most common chronic disease in adolescent girls, that's why the risk of disordered eating attitudes is highly prevalent among adolescent girls [7]. 
Dieting and unhealthy weight-control behaviors tended to be associated with weight gain, suggesting that they are ineffective in addition to being potentially harmful [8]. The nutritional requirement during adolescence remains the highest across the lifespan [10]. Adolescent girls are at a greater need for nutritional requirement than boys because of loss of energy during periodic menstrual episodes [11] and high metabolic rate due to stress. Disordered eating attitude can lead to a number of immediate health problems, such as iron deficiency anemia, deteriorating bone health and dental caries, undernutrition, obesity and eating disorders [12]. After controlling for baseline socio-demographic confounders, eating disorder was observed positively associated with new-onset obesity at age 11.5 years, with new-onset high systolic and diastolic blood pressure at age 16 years. Eating disorders in mid childhood seem to be related to the development of obesity and anemia in adolescence [13].

Disturbed nutritional status and eating disorder among adolescents are of serious public health concern owing to their high prevalence and adverse influence on and physical health [14]. Currently, 15\% of youth aged 6-19 years are found to be overweight. On the other hand, eating disorders like anorexia nervosa, bulimia nervosa, and binge eating affect a much small percentage of adolescent population (1-3\%) but are of great concern given their serious health consequences [15]. This type of eating habits may lead to nutritional deficiency during adolescence which may have long term consequences such as delayed sexual maturation and lower final adult height [16]. In our neighbor country, studies concluded that disordered eating is more prevalent among overweight adolescent girls compared to their counterparts who were normal weight and underweight [17]. Anthropometric traits of the participants reveal that indices like BMI, WHR and BF\% were significantly higher among those participants who have disordered eating attitudes (score $\geq 5$ ) than those with normal eating attitudes (score < 5) [18].

The nutritional and health status of university students has now become a major public health concern. University students are especially vulnerable to disordered eating behaviors due to stress factors associated with academic prestige, independence and social acceptance. There is no such study has been conducted to highlight disturbed eating attitudes and its association with health and nutritional status of adolescent girls in Pakistan. It is significant to explore these relationships among the university students because they face risks of experiencing negative psychological disturbance and engaging in disordered eating behaviors.

\section{Materials and Methods}

\subsection{Study Population and Selection Criteria}

The study population was university students at University of Peshawar and University of Agriculture Peshawar, KP- Pakistan. The study protocol was approved from the institutional research and ethics board of Faculty of Nutrition Sciences, The University of Agriculture
Peshawar. A total of 250 participants fulfill the study criteria and provided information in specific coded number questionnaires. From each University, 125 female students (both boarder and non-boarder; undergraduates) were randomly selected. The sole selection criteria included university girls aged 17 to 23 years, who were apparently healthy and free from any chronic disease. A signed consent forms were taken from the students before starting the data collection.

\subsection{Data Collection Procedure}

The questionnaires were completed by students in their classrooms under the standardized direction of welltrained nutrition research assistants. To protect the participant's privacy, students were led to a private area to measure height, weight, waist \& hip circumferences, blood pressure, glucose and hemoglobin levels. All nutrition research assistants were trained on research conduction, question answering, anthropometric and biochemical measurements. WHO anthropometric procedure was used to measure the height, weight, BMI, waist and hip circumferences of adolescent girls (WHO, 1995).

\subsection{Anthropometric Measurements}

Beam scale was used to measure the individual's weight nearest to $0.01 \mathrm{~kg}$ while height by using height board nearest to $0.01 \mathrm{~cm}$. The waist circumference was measured through measuring tape by placing between iliac crest and lower rib margin around the abdomen midway. The readings were taken to the nearest $0.1 \mathrm{~cm}$ and the individuals were categorized as normal $<80 \mathrm{~cm}$, overweight $80-88 \mathrm{~cm}$ and obese $>88 \mathrm{~cm}$. The measuring tape was placed around the buttocks for measuring hip circumference nearest to $0.1 \mathrm{~cm}$. BMI was calculated from weight/height readings and individuals nutritional status were categorized in Table 1.

Table 1. WHO Body Mass Index classification

\begin{tabular}{lc}
\hline BMI & Nutritional Status \\
\hline$<18.5$ & Under weight \\
$18.5-24.9$ & Normal \\
$25.0-29.9$ & Over weight \\
$>30.0$ & Obese \\
\hline
\end{tabular}

Similarly, WHR was designed from the waist and hip readings and data was equated with international classifications to establish the subjects' nutritional status as Andriod shape (WHR >0.8) and Gynoid shape (WHR<0.8).

\subsection{Hemoglobin, Glucose and Blood Pressure Assessment}

Hemoglobin concentration was estimated by the cyan method using hemoglobin analyzer. It is measured in terms of g/dl. Cuvette tube was pre-filled manually with Cyanmethhemoglobin reagent. It was incubated for 5 minutes and finally readings were noted. Glucometer was used to determine the random blood glucose level. A simple and feasible finger prick method was used for glucose level determination by transferring 2-3 drops of 
whole blood in to a disposable. Results were recorded in $\mathrm{mg} / \mathrm{dl}$. Blood pressure of the adolescent girls was recorded by using sphygmomanometer. The subjects were seated in a comfortable position and the right arm fully exposed for taking the BP reading. Two readings of both systolic and diastolic blood pressure were taken at least 5 to 10 minutes apart and the mean of the two measurements was calculated and recorded.

\subsection{Eating Attitudes Test-26}

Eating attitude of the girls was evaluated using the Eating Attitude Test-26 (EAT-26). EAT-26 is a validated self-administered questionnaire widely used to measure symptoms and characteristics of eating disorders. EAT-26 test has three sub-scales, Dieting; showing the number of girls who were on diet, Bulimia; subjected to extreme intake of food having no sense of controlling eating and oral control; being characterized by having orally control on food. Permission to use the EAT-26 questionnaire for current study has been sought through email from the concerned authorities. The EAT-26 was originally designed as an objective measure of the symptoms of anorexia nervosa. The girls were divided in to two groups i-e anorexic $($ EAT-26 score $=>20)$ and non-anorexic $($ EAT-26 score $=$ less than 20).

\subsection{Body Image and Health Characteristics}

A questionnaire was developed to evaluate body image of the girls, and was used to determined either they are satisfied or dissatisfied from their body image because girls have more perception about their body appearance and want to be look slimmer and smart. Health related questions including taking medicine, supplements, admitted at hospital in last 6 months, feel fresh in morning, sleep status and walking exercise were asked in personal to investigate the current health status of the cohort.

\subsection{Statistical Analysis}

Different files for each dataset (socioeconomic, anthropometry, nutritional \& health status, eating attitude and body image) were generated to minimize data entry errors in SPSS (IBM SPSS statistics 21). Each data set was containing a common variable including specific codes assigned to each study subject. Data was explored through descriptive statistics helped to determine proper statistical techniques for data analysis. An independent t-test was used to determine whether there was a statistically significant difference in anthropometrics, health measurements, and dietary characteristics between the groups (i.e. anorexic and non- anorexic groups). Pearson Chi-square statistic was used to test the association of categorical variables with girl's nutritional status groups. Health and nutritional risk factors for anemia in girls was identified using logistic regression. For exploring the association between anemia and its risk factors in the logistic regression analysis odds ratios (OR) and their corresponding 95\% confidence intervals (CI) were estimated. To explore the unadjusted correlation between the risk of anemia and each factor Univariate logistic regression was first executed. Multivariate logistic regression was then performed by putting all variables into the models to get odd ratio controlled for confounders. The Wald test was reported at $\mathrm{p}<0.05$.

\section{Results}

EAT-26 is the most widely used standardized selfreport measure of symptoms and concern characteristics of eating disorder, so we calculated the mean scores of Eating Attitude (EAT) and its subscales i.e. dietary factor, bulimia, oral control; and 'body image score' of the cohort. The mean score of EAT score was $18 \pm 10.5$, while for Dieting, Bulimia and Oral Control were 8.5 $\pm 7,3.20 \pm 2.59$ and 6.36 \pm 4.41 respectively. Similarly, mean body image score of the girls was $20 \pm 9$. Mean EAT-26 and its subscales scores were below but close to cut-off value of 20 showing overall higher tendency towards poor eating in the study cohort (Table 2).

Differences in socioeconomic characteristics, health \& nutritional status and body image score of the girls were explored among the EAT groups (i.e. anorexic and nonanorexic groups). No statistical differences in mean age and family income of the groups were evident $(\mathrm{p}>0.05)$. However, more anorexic than non-anorexic girls were living in joint family system compare to nuclear (33\% versus 20\%, $\mathrm{p}<0.05$ ) (Table 3 ).

The prevalence of malnutrition and body image dissatisfaction were categorized on the basis of nutritional status (BMI, WC, WHR and Hb) by EAT groups. Based on BMI and WC, more anorexic girls were found overweight and obese in comparison to the rest $(\mathrm{p}<0.05)$. Statuses of body shape being android or gynoid as well as anemia were found similar among the groups ( $p>0.05)$. Interestingly, our results showed that of the adolescent girls with normal BMI values, 53.60\% still suffered from anorexia (eating disorder) as diagnosed by EAT-26. Overweight participants were found to be more likely to have eating disorders in relation to underweight adolescents (Table 4).

There are specific predictors related to disturbed eating attitudes that adversely affect the health status of the adolescent girls. These health characteristics included current status of any medicine use, admission in the hospital in the last 6 months, any supplements taken, feeling freshness in the morning, sleep status, physical activity level and satisfaction about home. Differences in all of the health characteristics except for sleep status, freshness in the morning and physical activity were statistically non-significant among the groups ( $p>0.05)$. More anorexic girls showed less freshness in the morning; disrupted sleep and low physical activity $(\mathrm{p}<0.05)$. There is a reciprocal relationship between body image, diet, and exercise. Exercise and eating behaviors are biological factors responsible for proper maintenance of body weight and stature (Table 5).

As $44 \%$ of the cohort was anemic, so association of eating attitude of girls with the prevalence of anemia was explored, by controlling confounding factors. The association of various predictors on the occurrence of anemia in the university girls both adjusted and unadjusted results were recorded. Age was found a positive predictor of anemia in the unadjusted analysis; a unit change in age enhances 
0.88 times chances of anemia in girls (OR: 0.88, 95\% CI: 0.77 - 0.99; $\mathrm{p}<0.05)$. Underweight girls were more likely anemic than normal girls (Unadjusted OR: 1.11, 95\% CI: $0.58-2.13$; $\mathrm{p}<0.01$ ); while in the adjusted analysis, this association became stronger (Adjusted OR: 0.80, 95\% CI: 0.36-1.78; $\mathrm{p}<0.001)$. EAT-Score was found in strong association with anemia in both unadjusted (OR: 1.04, 95\% CI: 1.01-1.06) and adjusted analysis (OR: 1.05; 95\% CI: 1.01-1.09). In the same way, dieting score was slightly associated with anemia in both unadjusted (OR: 1.03, 95\% $\mathrm{CI}$; 1.0-1.07, $\mathrm{p}<0.05$ ) and adjusted (OR: 1.06, 95\% CI: 1.01 - 1.10, $\mathrm{p}<0.05)$ analysis. Girls with Bulimia and oral control have shown no association with occurrence of anemia in both adjusted and unadjusted analysis. Girls who were dissatisfied with their body image were more likely to be anemic than their counterpart in the unadjusted analysis; however this association diminished in the adjusted analysis. Among the health factors, girls with symptoms of anxiety, depression and stress were more likely to be anemic than their counterpart; this association remain significant in both analysis. Similarly, use of nutritional supplement was found related with anemia in the adjusted analysis suggesting significant role of supplementation in minimizing risk of anemia in girls. Finally, girls unhealthy dietary pattern was found a significant predictor of anemia; girls with disturbed eating pattern were about 5 times more likely at the risk of anemia in comparison to their counterparts $(p<0.001)$ (Table 6).

\section{Discussion}

The findings of the current study suggested that there was likelihood towards under eating rather than over eating as girls have more perception about their body shape as reported by [19]. An increase in body image score indicates higher level of dissatisfaction about body image. Dissatisfaction about body image in girls may lead to poor dietary habit and practices. A study showed that $29.2 \%$ of young girls had EAT-26 scores of 20 or higher, suggesting highly disordered eating attitudes and behaviors. A different study, conducted on a rural college campus, found that $17 \%$ of $18-19$ year old respondents fell in the high risk category for developing an eating disorder based on their EAT-26 score among ethnic Fijian city girls [20]. Our findings suggested that university students were at risk of developing eating disorders as reported previously in different settings; a study of abnormal eating attitude and weight loss behaviors of college girls was reported in Johannesburg, South Africa [21]. Szabo and Hollands (1997) reported that the mean EAT-26 score increased with advancing grades [22].

Though detailed socio-demographic information were not collected in current study; however several previous studies have shown association of eating patterns and habits with certain socio-demographic characteristics. The tendency of socioeconomic position being associated with dietary habits is shown to be stronger among girls than boys [23]. However, it is often hard to measure socioeconomic position in a good way while investigating young people as they tend to show an inaccurate reporting of parental income, education and occupation [24]. Our findings are in contrast with these results; no difference in mean income between the groups was evident in the current study. This may be due to the fact that the current cohort was enrolled in academic settings where girls from both EAT groups might have shared similar socioeconomic background. In current study, mean age of the groups were not different. However, age was found a risk factor for eating habits in previous research studies; older adolescents were at higher risk for eating unhealthy attitudes than younger adolescents [23]. Additionally, young girls particularly in school and colleges, spend more time with friends, where eating behaviour represents an important part of socialization and recreation. Group conformity is considered as an important determinant of food selection because students often are seeking peer approval and social identity. The peer influence increases and the parental influence declines with increase in age [25].

The plausible explanation for our finding can be provided by elucidating that eating disorders are morbidities with psychological basis, even individuals with normal body mass index can have likelihood of these disorders. Thus, it depends, only in part, on the actual body mass [26]. Eating disorders particularly anorexia nervosa is reported to disrupt several system with resultant complications of metabolic diseases. Particularly, anorectic patients have been reported to die at a premature age possibly from medical complications [27]. This disconcerting information should come in the knowledge of such individuals suffering from the disorder or at a high risk of developing one, who involve grossly in unhealthy dieting particularly females. Increasing prevalence of overweight and obesity in the Asian context has been associated with less physical activities and a nutrition transition characterized by increased consumption of western diets high in refined carbohydrates, added sugar and fat [28]. Furthermore, according to the results of the present study, eating attitudes influenced the body image. It has been established that obese participants followed an unhealthy diet more often than any other group. Overweight and underweight participants followed a diet more often than the normal participants; however, this difference was not statistically significant. According to the literature, people who tend to follow unhealthy diets are, in most of the cases, either obese or underweight [29].

Our findings supported by a study stated that there is a strong association between body image dissatisfaction and increased risk for physical and emotional complications such as unnecessary dieting and depression [30]. Many insomniacs' adults reported that the improvement of good sleep habits in adolescence is very critical. More evident suggested that adolescents and youth go to sleep later at night and to sleep for late time than do prepubescent children [31]. Nmor et al. (2014) carried out a study and found that female students (30.4\%) always slept well compared to male students (17.3\%), while $28.6 \%$ and $32.7 \%$ of female and male students had an average sleeping condition but it was not significantly different ( $>0.05$ ). Moreover, $69.2 \%$ and $64.3 \%$ of male and female students were taking breakfast respectively. The mean score for healthy eating behaviors of the male and female students were $28.08 \pm 4.8$ and $28.04 \pm 5.4$ respectively, but was statistically non-significant $(\mathrm{p}>0.05)$. It was contrast 
with our findings because there was a significant different $(p<0.01)$ among the healthy behaviors of the female students. Sleeping for longer duration was related to various unhealthy dietary behaviors, the main finding of the current study was that mostly in adolescents with longer sleep duration, they consumed more frequencies of fast food and sweetened beverages [32]. Whereas another German study on children and adolescent suggested that short sleepers mostly consumed fast food and soft drinks in both genders while long sleeper's girls was higher intake of sweets [33] (Hitze et al, 2009). Short sleeper's individuals have greater desire to feeling fatigue and tiredness which leads to physical inactivity as reported by a study that about $40 \%$ of short-sleeper adolescents reported waking up tired [34]. The lethargic responses of short sleeper's individuals supported by cross-sectional studies in children and adolescents have found short sleep durations to be linked with compact contribution in structured sports [35].
An Indian study conducted in social welfare hostel on health status of early adolescent girls, revealed that as per new guidelines of India government, 56.4\% was undernourished and 30\% was having clinical anemic in 420 adolescent girls [36]. Another study in adolescent girls of rural area suggested that both in univariate and multivariate logistic regression analysis, low iron intake and vegetarian diet showed significant association with anemia recorded 59.8\% [37]. There are few clinical studies on association of anemia with anxiety and depressive disorders. Lozoff et al. (2000) found that children with severe chronic iron deficiency in infancy had a greater prevalence of anxiety, depression and attention problems [38]. In a study conducted on association between psychiatric disorder and IDA among children and adolescent. In a total of 2957, it was concluded that iron deficiency anemia increased the risk of psychiatric disorders including psychiatric anxiety and depressive disorder [39].

Table 2. Mean score of Eating Attitude and Body Image of the Cohort $(n=250)$

\begin{tabular}{ccc}
\hline Characteristics & Mean \pm SD & Range \\
\hline EAT - Score* & $18 \pm 10.5$ & $0-66$ \\
Dieting factor & $8.5 \pm 7$ & $0-30$ \\
Bulimia & $3.20 \pm 2.59$ & $0-12$ \\
Oral control & $6.36 \pm 4.41$ & $0-23$ \\
Body image score & $20 \pm 9$ & $2-54$ \\
\hline
\end{tabular}

*EAT= Eating Attitude Test Score

Table 3. Socioeconomic characteristics of the girls on the basis of EAT group $(n=250)$

\begin{tabular}{|c|c|c|c|c|}
\hline Characteristics & EAT Groups & & & p-value \\
\hline \multirow{3}{*}{ Age (year) } & & \multicolumn{3}{|c|}{ Mean \pm SD } \\
\hline & Anorexic (n=69) & \multicolumn{2}{|c|}{$21.8 \pm 2.9$} & \multirow{2}{*}{ NS } \\
\hline & Non Anorexic $(\mathrm{n}=181)$ & & & \\
\hline \multirow[t]{2}{*}{ Family Income (Rs.) } & Anorexic (n=69) & \multicolumn{2}{|c|}{$70 \pm 20$} & \multirow{2}{*}{ NS } \\
\hline & Non Anorexic $(\mathrm{n}=181)$ & \multicolumn{2}{|c|}{$65 \pm 19$} & \\
\hline \multirow{4}{*}{ Family type } & & \multicolumn{2}{|c|}{ N (\%) } & \multirow{4}{*}{$<0.05$} \\
\hline & & Joint & Nuclear & \\
\hline & Anorexic (n=69) & $23(33 \%)$ & 46 (67\%) & \\
\hline & Non Anorexic $(\mathrm{n}=181)$ & 37 (20\%) & $144(80 \%)$ & \\
\hline
\end{tabular}

*EAT= Eating Attitude Test; NS=Not Significant

Table 4. Prevalence of malnutrition by EAT group

\begin{tabular}{|c|c|c|c|c|}
\hline \multirow{2}{*}{\multicolumn{2}{|c|}{ Characteristics }} & No. of girls & \multicolumn{2}{|c|}{ p-value } \\
\hline & & Anorexic $(n=69)$ & \multicolumn{2}{|c|}{$\begin{array}{c}\text { Non Anorexic } \\
(n=181)\end{array}$} \\
\hline \multirow{4}{*}{ BMI } & Normal (18.5-24.9) & $53.60 \%$ & $55.20 \%$ & \multirow{4}{*}{0.002} \\
\hline & Underweight $(\mathrm{BMI}<18.5)$ & $8.70 \%$ & $26.00 \%$ & \\
\hline & Overweight (BMI 25-29.99) & $26.10 \%$ & $13.80 \%$ & \\
\hline & Obese (BMI>30) & $11.60 \%$ & $5.00 \%$ & \\
\hline \multirow{3}{*}{ Central obese (WC) } & Normal $(\mathrm{WC}<80)$ & $46.40 \%$ & $65.20 \%$ & \multirow{3}{*}{0.013} \\
\hline & Overweight (WC=80-88) & $24.60 \%$ & $19.90 \%$ & \\
\hline & Central OB (WC >88) & $29.00 \%$ & $14.90 \%$ & \\
\hline \multirow{2}{*}{ WHR } & Gynoid shape & $79.70 \%$ & $85.10 \%$ & \multirow[t]{2}{*}{ NS } \\
\hline & Android shape & $20.30 \%$ & $14.90 \%$ & \\
\hline \multirow[t]{2}{*}{$\mathrm{Hb}$} & Anemic & $44.90 \%$ & $37.60 \%$ & \multirow[t]{2}{*}{ NS } \\
\hline & Normal & $55.10 \%$ & $62.40 \%$ & \\
\hline
\end{tabular}

$\mathrm{BMI}=$ body mass index; $\mathrm{WC}=$ waist circumference; $\mathrm{WHR}=$ waist to hip ratio; $\mathrm{Hb}=\mathrm{Hemoglobin}$ 
Table 5. General health characteristics of girls by EAT group

\begin{tabular}{|c|c|c|c|c|}
\hline \multirow{2}{*}{ Characteristics } & \multirow{2}{*}{ N (\%) } & \multicolumn{2}{|c|}{ Eating Behaviors } & \multirow{2}{*}{$\mathrm{P}$ value } \\
\hline & & Anorexia & Non-anorexia & \\
\hline \multicolumn{5}{|l|}{ Taking Medicine } \\
\hline Yes & $54(21.6 \%)$ & $14(20.3 \%)$ & $40(22.1 \%)$ & NS \\
\hline No & $196(78.4 \%)$ & $55(79.7 \%)$ & $141(78 \%)$ & \\
\hline \multicolumn{5}{|c|}{ Admitted in Hospital (last 6 month) } \\
\hline Yes & $10(14 \%)$ & $4(5.8 \%)$ & $6(3.3 \%)$ & NS \\
\hline No & $240(96 \%)$ & $65(94.2 \%)$ & $175(96.7 \%)$ & \\
\hline \multicolumn{5}{|l|}{ Supplements } \\
\hline Yes & 35 (84\%) & $31(44.95 \%)$ & $54(30 \%)$ & NS \\
\hline No & $165(66 \%)$ & $38(55.1 \%)$ & $127(70.2 \%)$ & \\
\hline \multicolumn{5}{|c|}{ Feel Fresh in Morning } \\
\hline Yes & $132(53 \%)$ & $34(49.3 \%)$ & $98(54.1 \%)$ & $<0.05$ \\
\hline No & $118(47.2 \%)$ & $35(60 \%)$ & $83(46 \%)$ & \\
\hline \multicolumn{5}{|l|}{ Sleep Status } \\
\hline Normal sleep & $154(62 \%)$ & $34(49.3 \%)$ & $120(66.3 \%)$ & $<0.05$ \\
\hline Disrupted sleep & $96(38.4 \%)$ & $35(60 \%)$ & $61(34 \%)$ & \\
\hline \multicolumn{5}{|l|}{ Walk } \\
\hline Yes & $171(68.4 \%)$ & $22(32 \%)$ & $149(82.3 \%)$ & $<0.05$ \\
\hline No & $79(31.6 \%)$ & $47(68.1 \%)$ & $32(18 \%)$ & \\
\hline \multicolumn{5}{|c|}{ Feeling about Home } \\
\hline Satisfied & 224 (89.6\%) & $53(77 \%)$ & 171 (94.5\%) & NS \\
\hline Non-Satisfied & $26(10.4 \%)$ & $16(10.4 \%)$ & $10(5.5 \%)$ & \\
\hline
\end{tabular}

Table 6. Eating attitudes and nutritional related risk factors of anemia in adolescent girls

\begin{tabular}{|c|c|c|}
\hline Predictors & Unadjusted OR (95\% CI) & Adjusted OR (95\% CI) \\
\hline Age & $0.88(0.77 ; 0.99)^{*}$ & $1.00(0.84 ; 1.19)$ \\
\hline \multicolumn{3}{|l|}{ Nutritional Status } \\
\hline Normal & Reference & Reference \\
\hline Under weight & $2.98(1.59 ; 5.59)^{* *}$ & $4.73(2.02 ; 11.07)^{* * *}$ \\
\hline Over weight & $1.11(.58 ; 2.13)$ & $0.80(0.36 ; 1.78)$ \\
\hline \multicolumn{3}{|l|}{ EAT-26 } \\
\hline EAT-Score & $1.04(1.01 ; 1.06)^{* *}$ & $1.05(1.01 ; 1.09)^{* *}$ \\
\hline Dieting Score & $1.03(1.0 ; 1.07)^{*}$ & $1.06(1.01 ; 1.10)^{*}$ \\
\hline Bulimia & $1.09(0.99 ; 1.21)$ & $0.93(0.81 ; 1.07)$ \\
\hline Oral & $1.02(0.97 ; 1.08)$ & $0.97(0.90 ; 1.05)$ \\
\hline \multicolumn{3}{|l|}{ Body image } \\
\hline Satisfied & Reference & Reference \\
\hline Dissatisfied & $1.92(1.14 ; 3.22)^{*}$ & $1.82(0.92 ; 3.60)$ \\
\hline \multicolumn{3}{|l|}{ Health status } \\
\hline Anxiety/depression/stress (Yes) & $1.89(1.03 ; 3.48)^{*}$ & $3.05(1.38 ; 6.74)^{* *}$ \\
\hline Supplements Not taken ${ }^{1}$ & $2.11(1.20 ; 3.71)$ & $4.23(1.95 ; 9.16)^{* * *}$ \\
\hline Medication (Yes) $^{2}$ & $1.08(0.56 ; 2.05)$ & $1.07(0.40 ; 2.37)$ \\
\hline Admitted (Yes) ${ }^{3}$ & $1.32(0.56 ; 3.09)$ & $0.68(0.24 ; 1.90)$ \\
\hline \multicolumn{3}{|l|}{ Tertiles of unhealthy dietary pattern } \\
\hline $3^{\text {rd }}$ Tertile & $5.21(2.67 ; 10.16)^{* * *}$ & $4.88(2.25 ; 10.57)^{* * *}$ \\
\hline $2^{\text {nd }}$ tertile & $1.25(0.63 ; 2.47)$ & $0.90(0.40 ; 2.03)^{* * *}$ \\
\hline $1^{\text {st }}$ Tertile (Healthy Pattern) & Reference & Reference \\
\hline
\end{tabular}

${ }^{*} \mathrm{p}<0.05$; ** $\mathrm{p}<0.01,{ }^{* * *} \mathrm{p}<0.001$; Medical Problem: ${ }^{1}$ on any iron supplement (Yes versus $\mathrm{No}$ ); ${ }^{2}$ on medication due to general or specific health problem (Yes versus No) ${ }^{3}$ admitted at hospital in last six months (Yes versus No)

\section{Conflict of Interest}

The authors have no conflict of interest regarding the paper.

\section{Acknowledgments}

The authors are grateful to university girls who participated in the study. We also indebted of administrative staff of both universities for support and nutrition assistants for hard working.

\section{References}

[1] Tsai, M., Chang, Y., Lien, P. and Wong, Y, "Survey on eating disorders related thoughts behaviors and dietary intake in female junior high school students in Taiwan", Asia Pacific Journal of Clinical Nutrition, 20. 196-205. 2011.

[2] Costa, C., Ramos, E., Severo, M., Barros, H. and Lopes, C, "Determinants of eating disorders symptomatology in Portuguese adolescents”, Archives of Pediatrics and Adolescent Medicine, 162. 1126-1132. 2008.

[3] Kann, L., Warren, C.W. and Harris, W.A, "Youth Risk Behavior Surveillance-United States 1995”, Journal of School Health, 66. 365-377. 1996. 
[4] Neumark-Sztainer, D., Paxton, S.J., Hannan, P.J., Haines, J. and Story, M, "Does Body Satisfaction Matter? Five-year Longitudinal Associations between Body Satisfaction and Health Behaviors in Adolescent Females and Males”, Journal of Adolescent Health, 39. 244-251. 2006.

[5] Patton, G.C., Selzer, R., Coffey, C., Carlin, J.B. and Wolfe, R, "Onset of adolescent eating disorders: population based cohort study over 3 years”, British Medical Journal, 318. 765-768. 1999.

[6] Fairburn, C.G. and Paul, J.H, "Eating disorders", The Lancet, 361. 407-416. 2003.

[7] Alfoukha, M.M., Ayman, M.H.M. and Manar, A.B, "Social and Psychological Factors Related to Risk of Eating Disorders Among High School Girls", The Journal of School Nursing, 1-9. 2017.

[8] Goldschmidt, A.B., Melanie, M.W., Tse-Hwei, J.C., Whitney, E., J., Nicole, L. and DianneNeumark, S, "Fifteen-year Weight and Disordered Eating Patterns Among Community-based Adolescents”, American Journal of Preventive Medicine, 54.e21-e29. 2018.

[9] Wakeling, A, “Abnormal eating attitudes in London schoolgirls a prospective epidemiological study: outcome at twelve months”, Psychol Med, 20. 382-394. 1990.

[10] World Health Organization. Obesity: Preventing and Managing the Global Epidemic. WHO consultation. WHO Technical Report Series no. 894. Geneva: World Health Organization, 2000.

[11] National Institute of Nutrition. Dietary Guidelines for Indian. 2011. Available at: ninindia.org/DietaryguidelinesforIndians- Finaldraft.pdf.

[12] Centers for Disease Control and Prevention (CDC). Guidelines for school health programs to promote lifelong healthy eating. Morb Mortal Wkly Rep, 45:1-37. 1996.

[13] Reed, Z.E., Nadia, M., Cynthia, M.B., George, D.S. and Kaitlin, H.W, "Assessing the causal role of adiposity on disordered eating in childhood, adolescence, and adulthood: a Mendelian randomization analysis”, Am J Clin Nutr, 106. 764-72. 2017.

[14] Zipfel, S., Owe, B.L., Reas, D.L., Deter, H. and Herzog, W, “Long term prognosis in anorexia nervosa: lessons from a 21-year follow up study”, The Lancet, 355.721-722. 2000.

[15] Nicklas, T.A., Myers, L., Reger, C., Beech, B. and Berenson, GS, "Impact of breakfast consumption on nutritional adequacy of the diets of young adults in Bogalusa Louisiana: ethnic and gender contrasts”, Journal of the American Dietetic Association, 1432-1438. 1998.

[16] Chugh, R. and Puri, S, “Affluent adolescent girls of Delhi: eating and weight concerns”, Br J Nutr, 86.535-42. 2001.

[17] Mallick, N., Susmita, M. and Subha, R, "Eating attitudes and its relationship with nutritional status: a micro level study on a group of adolescent girls in the city of Howrah West BengalInt”, J Adolesc Med Health, 2017.

[18] Tosevski, D.L., Milovancevic, M.P. and Gajic, S.D, "Personality and psychopathology of university students”, Curr Opin Psychiatry, 23. 48-52. 2010.

[19] Steiger, H., Seguin, J.R., Million, T., Blaneyu, PH. and David, R, 1999. Eating disorders: Anorexia nervosa and bulimia nervosa. Oxford textbook of psychopathology, Oxford University Press, New York. 365- 88. 1999.

[20] Becker, A.E., Burwell, R.A., Gilman, S.E., Herzog, D.B. and Hamburg, P, "Eating behaviors and attitudes following prolonged exposure to television among ethnic Fijian adolescent girls”, British. J. Psych, 180.509-514. 2002.

[21] Visser, T., Notelovitz, C., Szabo, P. and Fredericks, N, “Abnormal eating attitudes and weight-loss behaviour of adolescent girls attending a traditional Jewish high school in Johannesburg South Africa”, S. Afr. J. Clin. Nutr, 4. 208-216. 2002.

[22] Szabo, C.P. and Hollands, C, "Abnormal eating attitudes in secondary-school girls in South Africa: a preliminary study", S. Afr. Med. J, 87. 524-526. 1997.
[23] Nelson, M.C., Kocos, R., Lytle, L.A. and Perry, CL, "Understanding the perceived determinants of weight-related behaviors in late adolescence: a qualitative analysis among college youth”, J. Nutr. Edu. Behvr, 4. 287-92. 2009.

[24] French, S.A., Story, M., Neumark-Sztainer, D., Fulkerson, J.A and Hannan P, "Fast food restaurant use among adolescents: associations with nutrient intake food choices and behavioral and psychosocial variables”, Inter. J. Obes, 12. 1823-33. 2001.

[25] Vereecken, C.A., Inchley, J., Subramanian, S.V., Hublet, A. and Maes, L, "The relative influence of individual and contextual socio-economic status on consumption of fruit and soft drinks among adolescents in Europe”, Eur. J. Pub. Health, 3. 224-232. 2005.

[26] Nicklas S, Issanchou S, Children and food choice. Understanding consumers of food products In: L. Frewer \& H. van Trijp (ed.) 2007:329-358. Cambridge: CRC Press.

[27] Mitchell, J. and Crow, S, "Medical complications of anorexia nervosa and bulimia nervosa”, Curr Opin Psychiatry, 19. 438-443. 2006.

[28] Popkin, B, "Global nutrition dynamics: the world is shifting rapidly toward a diet linked with noncommunicable diseases”, $\mathrm{Am}$ J Clin Nutr, 84. 289-98. 2006.

[29] Golden, N.H., Jacobson, M.S., Sterling, W.M. and Hertz, S, "Treatment goal weight in adolescents with anorexia nervosa: use of BMI percentiles", The International Journal of Eating Disorders, 41. 301-6. 2008.

[30] Ge, X., Glen, H., Elder, J.R., Mark, R. and Christine, C, "Pubertal Transitions, Perceptions of Being Overweight, and Adolescent Psychological Maladjustment: Gender and Ethnic Differences”, Social Psychology Quarterly, 64. 363-375. 2001.

[31] Dahl RE, Charskadon MA. Sleep and its disorders in adolescence. principles and practice of sleep medicine in the child. Philadelphia: WB Saunders, 19-27. 1995.

[32] Judith, N., Kehi, H.N. and Jephtha, C.N, "Eating behaviours of university students in Southern Nigeria: an evaluation of sex differences”, Sci. J. Pub. Health, 1. 23-37. 2014.

[33] Hitze, B., Bosy-Westphal, A., Bielfeldt, F., Settler, U., PlachtaDanielzik, S., Pfeuffer, M., Schrezenmeir, J., Mönig, H. and Müller, M.J, "Determinants and impact of sleep duration in children and adolescents: data of the Kiel Obesity Prevention Study”, Eur. J. Clin. Nutr, 63. 739-746. 2009.

[34] Knutson, K.L, “The association between pubertal status and sleep duration and quality among a nationally representative sample of U. S. adolescents”, Amr. J. Human Biology, 17. 418-424. 2005.

[35] Vonkries, R., Toschke, A.M., Wurmser, H., Sauerwald, T. and Koletzko, B, "Reduced risk for overweight and obesity in 5-and 6y-old children by duration of sleep-a cross-sectional study”, Int. J. Obes, 26. 710-716. 2002.

[36] Wasnik, V., Rao, B.S. and Rao, D, “A Study of the Health Status of Early adolescent Girls residing in Social Welfare Hostels in Vizianagaram district of Andhra Pradesh State India. Interl”, $J$. Collaborative Research on Internal Medicine \& Public Health, 1. 72-83. 2012.

[37] Kaur, S., Deshmukh, P.R. and Garg, B.S, "Epidemiological Correlates of Nutritional Anemia in Adolescent Girls of Rural Wardha”, Indian Journal of community Medicine, 31. 255-258. 2006.

[38] Lozoff, B., Jimenez, E., Hagen, J., Mollen, E. and Wolf, A.W, "Poorer behavioral and developmental outcome more than 10 years after treatment for iron deficiency in infanc”, Pediatrics, 4. E51. 2000.

[39] Chen, M., Tung-Ping, S., Ying-Sheue, C., Ju-Wei, H., Kai-Lin, H., Wen-Han, H., Tzeng-Ji, H. and Ya-Mei, B, “Association between psychiatric disorders and iron deficiency anemia among children and adolescents: a nationwide population-based study”, $B M C$ Psychiatry, 13. 161. 2013. 